\title{
Wushu Teaching Strategy and Development in Urban and Rural Schools
}

\author{
Zu-Gang Bai ${ }^{1 *}$ \\ ${ }^{1}$ Department of Physical Education, Hubei University of Chinese Medicine, Wuhan, Hubei, CHINA
}

Received 26 May 2017 • Revised 21 September 2017 • Accepted 12 November 2017

\begin{abstract}
Affected by economic factors, rural sports are far behind cities in equipment construction and faculty, among urban and rural physical education, martial arts teaching is a considerable important part. The paper utilizes comparative analysis method and relative number comparison method, starts from urban and rural martial arts teaching development and martial arts cultural inheritance two aspects to analyze urban and rural martial arts teaching existing gap. Firstly, by deepen analysis of urban and rural martial arts course setup forms, curricular class hour, curricular established items; it researches on urban and rural martial arts teaching development. Secondly, by analyzing urban and rural sports teachers attitudes toward martial arts teaching, urban and rural students comprehension status on martial arts as well as comprehension paths, it states martial arts inheritance issue in urban and rural martial arts teaching process, and for gap be-tween towns and countries, it further gets conclusions that urban and rural martial arts teaching have great gaps, city martial arts teaching course established forms are relative plentiful, arranged class hours are more, and items' contents selectivity is stronger, no matter students or teachers, their comprehension paths and behavioral attitudes toward martial arts teaching are better than rural teachers and students, by comparing, rural martial arts teaching is inferior to city ones.
\end{abstract}

Keywords: comparative analysis method, teaching strategy, physical education

\section{INTRODUCTION}

Martial arts culture represents Chinese cultural quintessence, is the representative of Chinese traditional cultural spirit. Inherit martial arts culture; carry forward martial arts spirits are of very important significances in Chinese sports all-round development. Therefore, numerous scholars have done relevant researches on it (Dai, 2012; Kant et al., 2017). The thesis started from Jinan city primary and secondary school martial arts course setup, martial arts teachers' educational levels, students' fondness level on martial arts to research, and presented that Jinan city martial arts teaching development should base on improving students' cultural literacy, strengthening their martial arts spirits inheritance, focus on course content richness and lecturing ways variety, and further stimulate students' learning enthusiasm ( $\mathrm{Li}$ and Mei, 2017; Eitel et al., 2017). Sun Bei-Bei by the article "Henan province vocational colleges' martial arts teaching status and countermeasures research", introduced Henan province vocational colleges' martial arts teaching conditions (Zheng, 2015; Lam and Muldner, 2017). The thesis started from the teaching current status, focused on analyzing their teaching tasks, teaching contents, and used students' satisfaction as evaluation criterion to make quantitative evaluation on their teaching quality. The thesis pointed out that Henan province martial arts teaching hadn't yet rapidly developed, martial arts course was almost occupied by football, basketball, badminton and else in physical education course, students' enthusiasm in martial arts learning was also not so high (Li et al., 2017; Sit and Brudzinski, 2017). Cheng Xin-Quan through the article "Shanghai universities overseas students' martial arts teaching development status and countermeasures research", stated overseas students' martial arts teaching relevant features (Atapattu et al., 2017; Cochrane and Davey, 2017). The thesis took Shanghai city as an example, studied martial arts development status in their learning course from the perspective of universities overseas students, and presented relative countermeasures for problems. The thesis pointed out that 


\section{Contribution of this paper to the literature}

- There is a big gap between urban and rural martial arts teaching.

- The teaching courses of urban martial arts are more abundant, and there are more courses arranged.

- Both students and teachers have better understanding and behavioral attitudes towards martial arts teaching than the rural teachers and students. In contrast, rural martial arts teaching is far less than urban martial arts teaching.

Shanghai city overseas students' martial arts teaching was affected by overseas students teaching features, it was relative advanced, and was demonstration of Chinese martial arts teaching, the teaching mode combined with foreign martial arts teaching relevant experiences, was major in students' self-learning, took students as teaching centers, focused on cultivating students' capacity, China should reference the teaching method.

Wushu teaching strategy is an important issue in the practice of Wushu teaching and is also a key and difficult point in the current teaching research. As the effective "way" to solve the problem of martial arts teaching effectiveness, martial arts teaching strategies for the deepening of martial arts teaching theory, or to martial arts teaching reform has important theoretical and practical significance (Zhang and Peng, 2017; Chase and Klahr, 2017). The fundamental problem of the martial arts teaching strategy mainly has the concept of martial arts teaching strategy, the characteristics, structure, type and formulation, etc., clear they help martial arts teachers in the teaching practice accurately martial arts teaching strategy, design, develop and use to achieve the goal of improving martial arts teaching effect (Lv, 2011; Falloon, 2017; Ballou and Springer, 2017). The paper starts from Chinese urban and rural martial arts teaching development, carries on researching, takes powerful cultural country construction target as main background and then analyzes urban and rural martial arts teaching differences that make contributions to shorten urban and rural education gap and speed up Chinese urban and rural integration process.

\section{THE RESEARCH METHODS}

\section{Comparative Analysis Basic Principle}

Comparative analysis refers to compare between correlated two indicators so as to show things attributes. According to research objects different attributes, it can be divided into single indicator comparison and multiple indicator comparison that is simple evaluation and comprehensive evaluation (Parks-Stamm et al., 2017). Principle that comparative analysis should adhere in practical operation process is comparability principle, its basic contents are as following (McLean et al., 2017):

Research object connotation and denotation comparability;

Research object time range comparability;

Research object computational method comparability;

Research object overall attributes' comparability;

By comparative analysis above comparison principles, adopt multiple target comparison that is comprehensive evaluation to analyze Chinese urban and rural martial arts education differences.

\section{The Relative Comparison Method}

Relative number comparison is a kind of analysis method that most common in comparative analysis, it is two mutual correlated indicators forming into comparative relationships so as to reflect research objects' quantitative relationships and then making comprehensive evaluation on them (Lai et al., 2017; Geller et al., 2017).

Therefore, utilize intensity relative number comparison method to make comparative analysis of urban and rural teachers and students martial arts teaching conditions, and then get relevant conclusions.

\section{RESEARCH PROCESS AND ANALYSIS}

Chinese education problem is always the focus of people's concerns, with imbalance urban and rural development, urban and rural education problem has also appeared great gaps. In urban and rural education, physical education is a main issue to promote to urban and rural education development and shorten gap (Guterman, 2017; Kinkead-Clark, 2017). Due to economic factors influences, rural sports is far behind cities in equipment construction and faculty, therefore, it takes martial arts teaching as an example to make accordingly analysis, relevant data is as Table 1. 
Table 1. Urban and secondary school martial arts teaching popularization conditions

\begin{tabular}{cccccc}
\hline & Item & Always have & Ongoing & Used to have & Have not \\
\hline \multirow{2}{*}{ Village } & Primary school & $0 \%$ & $15 \%$ & $30 \%$ & $55 \%$ \\
\cline { 2 - 6 } & Secondary school & $5 \%$ & $20 \%$ & $35 \%$ & $40 \%$ \\
\hline \multirow{2}{*}{ City } & Primary school & $3 \%$ & $25 \%$ & $25 \%$ & $47 \%$ \\
\cline { 2 - 6 } & Secondary school & $11 \%$ & $29 \%$ & $40 \%$ & $20 \%$ \\
\hline
\end{tabular}

Table 2. Urban and rural primary and secondary school martial arts course setup forms

\begin{tabular}{clccc}
\hline & Item & $\begin{array}{c}\text { Martial arts physical } \\
\text { education course }\end{array}$ & $\begin{array}{c}\text { Setting-up exercises during } \\
\text { class-break }\end{array}$ & $\begin{array}{c}\text { Extracurricular martial arts } \\
\text { training }\end{array}$ \\
\hline \multirow{2}{*}{ Village } & Primary school & $77.8 \%$ & $0 \%$ & $22.2 \%$ \\
\cline { 2 - 5 } & Secondary school & $54.5 \%$ & $18.2 \%$ & $27.3 \%$ \\
\hline \multirow{2}{*}{ City } & Primary school & $81.5 \%$ & $1.2 \%$ & $17.3 \%$ \\
\cline { 2 - 5 } & Secondary school & $60.2 \%$ & $21.3 \%$ & $18.5 \%$ \\
\hline
\end{tabular}

Table 3. Urban and rural primary and secondary school martial arts course class hours

\begin{tabular}{ccccccc}
\hline & & $\mathbf{2 ~ 6}$ class hours & $\mathbf{4} \mathbf{8}$ class hours & $\mathbf{8} \sim \mathbf{1 0}$ class hours & $\mathbf{1 0} \mathbf{1 2}$ class hours & $\mathbf{> 1 2}$ class hours \\
\hline \multirow{2}{*}{ Village } & Primary school & $22.2 \%$ & $55.6 \%$ & $22.2 \%$ & $0 \%$ & $0 \%$ \\
\cline { 2 - 7 } & Secondary school & $0.9 \%$ & $45.5 \%$ & $46.7 \%$ & $3.9 \%$ & $3.0 \%$ \\
\hline \multirow{2}{*}{ City } & Primary school & $23.0 \%$ & $56.2 \%$ & $18.7 \%$ & $1.1 \%$ & $1.0 \%$ \\
\cline { 2 - 7 } & Secondary school & $2.5 \%$ & $49.8 \%$ & $45.9 \%$ & $1.3 \%$ & $0.5 \%$ \\
\hline
\end{tabular}

Above is Chinese urban and rural primary and secondary school martial arts education popularization conditions, to better compare Chinese urban and rural martial arts education relative conditions, find out urban and rural education problems and shorten urban and rural gaps, now it makes comparative analysis of it, conducts comprehensive analysis from urban and rural martial arts course setup forms, class hours, setup items, curricular contents, comparative analysis process is as following, and gets conclusions according to relevant analysis (Hsieh and Tsai, 2017; Luo et al., 2017).

\section{Urban and Rural Martial Arts Course Setup Forms}

Martial arts culture is Chinese prolong culture, among urban and rural physical education, martial arts teaching is a considerable important part. In general, martial arts teaching develop in the form of physical education course, setting-up exercises during class-break, extracurricular training class and else so as to promote students' martial arts learning interests, stimulate their learning enthusiasm, relevant data is as Table 2.

Statistical Table 2 indicate that on a whole, city martial arts course setup, no matter in secondary school or primary school, both are major in physical education course; from the perspective of students' grades, primary school martial arts course setup is major in physical education course and martial arts extracurricular training class, while secondary school setup proportion in the two ways are relative lower.

\section{Urban and Rural Martial Arts Curricular Class Hours}

Except for curricular setup forms, curricular class hours are also important factors that affect martial arts teaching. Big class hours show that emphasis on martial arts teaching is high; on the contrary, it shows emphasis is low. Table 3 is urban and rural primary and secondary school martial arts class hours' conditions investigation table, make comparative analysis of it.

By comparative analysing Table 3, it can get conclusions that on a whole, city martial arts course class hours are higher, rural school is relative lower; from the perspective of students' grades, primary school martial arts course class hours are lower than that in secondary school, and city school proportion is larger, which shows city focuses on martial arts teaching in teenager teaching.

\section{Urban and Rural Martial Arts Course Setup Items}

For martial arts teaching, its teaching contents is very plentiful, youth boxing, long boxing, martial arts basic knowledge and others, all are main parts in their teaching. Therefore, to compare urban and rural martial arts teaching differences, now it carries out comparative analysis of their teaching contents and gets conclusions by analysis.

Analyze Table 4 data, and make comprehensive evaluation on it by drawing statistical figure and utilizing comparative analysis criterion, and get conclusions. it can get conclusions that Chinese city martial arts teaching is 
Table 4. Urban and rural primary and secondary school martial arts course setup items

\begin{tabular}{lcccc}
\hline & \multicolumn{2}{c}{ Village } & \multicolumn{2}{c}{ City } \\
\cline { 2 - 5 } & Primary school & Junior high school & Primary school & Junior high school \\
\hline Introduce martial arts knowledge & $22.2 \%$ & $18.2 \%$ & $25.8 \%$ & $19.3 \%$ \\
\hline Martial arts basic skills & $33.3 \%$ & $27.3 \%$ & $36.7 \%$ & $31.0 \%$ \\
\hline Youth boxing & $66.7 \%$ & $63.7 \%$ & $75.4 \%$ & $70.9 \%$ \\
\hline Five-step boxing & $11.1 \%$ & $72.7 \%$ & $15.6 \%$ & $73.9 \%$ \\
\hline Primary long boxing & $11.1 \%$ & $54.5 \%$ & $14.9 \%$ & $58.2 \%$ \\
\hline Pair exercise & $0.0 \%$ & $0.9 \%$ & $0.3 \%$ & $10.1 \%$ \\
\hline Equipment & $0.0 \%$ & $0.9 \%$ & $0.5 \%$ & $0.98 \%$ \\
\hline Self-complied routine & $0.0 \%$ & $0.0 \%$ & $0.1 \%$ & $0.3 \%$ \\
\hline Else & $11.1 \%$ & $0.9 \%$ & $10.8 \%$ & $11.3 \%$ \\
\hline
\end{tabular}

Table 5. Urban and rural sports teachers teaching attitudes towards martial arts course

\begin{tabular}{cccccc}
\hline \multirow{2}{*}{ Village } & & Very important & Necessary & General & No need \\
\cline { 2 - 6 } & Primary school & $2.8 \%$ & $30.5 \%$ & $50.0 \%$ & $16.7 \%$ \\
\hline \multirow{2}{*}{ City } & Secondary school & $12.8 \%$ & $30.2 \%$ & $46.5 \%$ & $10.5 \%$ \\
\cline { 2 - 6 } & Primary school & $3.5 \%$ & $36.7 \%$ & $47.9 \%$ & $11.9 \%$ \\
\cline { 2 - 6 } & Secondary school & $15.3 \%$ & $41.8 \%$ & $39.4 \%$ & $3.5 \%$ \\
\hline
\end{tabular}

major in establishing martial arts basic knowledge, youth boxing, long boxing, and five-step boxing, the contents is relative plentiful, while comparatively rural school martial arts teaching curricular contents is relative single, especially for primary and secondary school teaching that are far away from cities by comparison.

\section{The Satisfaction of Wushu Teaching in Urban and Rural Areas}

Relative number comparison is a kind of analysis method that most common in comparative analysis, it is two mutual correlated indicators forming into comparative relationships so as to reflect research objects' quantitative relationships and then making comprehensive evaluation on them (Taggart, 2017; Scott et al., 2017).

Therefore, utilize intensity relative number comparison method to make comparative analysis of urban and rural teachers and students martial arts teaching conditions, and then get relevant conclusions.

\section{Sports teachers' attitudes towards martial arts teaching}

As far as martial arts education is concerned, teachers and students' emphasis is considerable important to its development, due to comprehension levels on martial arts culture are different, the emphasis levels are also different.

Table 5 is urban and rural sports teachers' teaching attitudes towards martial arts course, to analyze them and get conclusion.

Analyze Table 5 data, and make comprehensive evaluation on it by drawing statistical figure and utilizing comparative analysis criterion, and get conclusions. it gets conclusions that city sports teachers' teaching attitudes towards martial arts course are better, most of them think martial arts teaching is very important, while rural school teachers' recognition level on martial arts knowledge is relative weaker (Ding et al., 2017). To shorten urban and rural gaps, improve teachers' sports awareness is crucial.

\section{Urban and rural students' martial arts comprehension conditions}

Student is carrier of sports development, for martial arts cultural inheritance and martial arts education development, students' comprehension level represents martial arts development process, and also reflects its development speed from the side.

Table 6 is Chinese urban and rural students' comprehension level on martial arts, of which it makes comparative analysis, compares data features and accordingly gets conclusions.

Analyze Table 6 data, and make comprehensive evaluation on it by drawing statistical figure and utilizing comparative analysis criterion, and get conclusions. It can get conclusion that city students' comprehension level on martial arts knowledge is higher, number of students that are very familiar with martial arts are more, while rural students, due to affected by education level and economic development, their comprehension on martial arts knowledge is lower, most of them are just with general comprehension (Mayer, 2017). Therefore, in order to shorten urban and rural education gaps, improve students' education level and sports awareness are crucial. 
Table 6. Urban and rural students' comprehension on martial arts

\begin{tabular}{ccccccc}
\hline & Very familiar & Basically comprehend & General & Don't comprehend & Don't know at all \\
\hline \multirow{2}{*}{ Village } & Primary school & $0.8 \%$ & $4.3 \%$ & $73.6 \%$ & $17.9 \%$ & $3.4 \%$ \\
\cline { 2 - 7 } & Secondary school & $2.6 \%$ & $17.1 \%$ & $64.8 \%$ & $13.2 \%$ & $2.3 \%$ \\
\hline \multirow{2}{*}{ City } & Primary school & $1.5 \%$ & $10.8 \%$ & $75.2 \%$ & $10.1 \%$ & $2.4 \%$ \\
\cline { 2 - 7 } & Secondary school & $4.7 \%$ & $18.1 \%$ & $76.4 \%$ & $0.6 \%$ & $0.8 \%$ \\
\hline
\end{tabular}

Table 7. Urban and rural students' martial arts comprehension paths

\begin{tabular}{ccccccccccc}
\hline & & Television & Network & Video disk & PE & The press & Novel & Match & Friends & Other \\
\hline \multirow{2}{*}{ Village } & Primary school & $42.8 \%$ & $18.4 \%$ & $3.1 \%$ & $22.3 \%$ & $0.4 \%$ & $5.1 \%$ & $1.7 \%$ & $2.3 \%$ & $3.9 \%$ \\
\cline { 2 - 12 } & Secondary school & $37.6 \%$ & $24.9 \%$ & $5.3 \%$ & $18.8 \%$ & $0.7 \%$ & $8.5 \%$ & $2.3 \%$ & $1.6 \%$ & $0.3 \%$ \\
\hline \multirow{2}{*}{ City } & Primary school & $41.7 \%$ & $19.2 \%$ & $2.5 \%$ & $22.9 \%$ & $1.1 \%$ & $6.0 \%$ & $3.5 \%$ & $2.9 \%$ & $0.2 \%$ \\
\cline { 2 - 11 } & Secondary school & $33.3 \%$ & $25.7 \%$ & $6.6 \%$ & $17.9 \%$ & $0.9 \%$ & $9.2 \%$ & $3.1 \%$ & $2.3 \%$ & $1.0 \%$ \\
\hline
\end{tabular}

\section{Urban and rural students' martial arts comprehension paths}

Among cities and villages, due to development speeds are different, their paths to comprehend martial arts knowledge are also very different, generally, television, network are main comprehension paths.

Table 7 is Chinese urban and rural students' martial arts comprehension path, of which it makes analysis, learns urban and rural martial arts knowledge acquiring paths differences and gets conclusion.

Analyze Table 7 data, and make comprehensive evaluation on it by drawing statistical figure and utilizing comparative analysis criterion, and get conclusions. It is clear that television and network are basic paths for urban and rural students comprehending martial arts knowledge, but due to economic conditions influence, city students also acquire martial arts knowledge by PE, video disk and other paths, while by comparing, rural school students' acquiring ways are relative single (Paredes, 2017).

\section{Wushu Teaching Strategy}

Wushu teaching strategy is derived from the sports teaching strategy, or the application of PE teaching strategy in Wushu teaching. Martial arts teaching strategy is in order to achieve the purpose of Wushu teaching, martial arts teaching task, martial arts teachers in martial arts teaching activity according to the actual situation of teaching and adopt effective teaching procedures, measures, methods, techniques and control way of the overall consideration, the design and operation. In general, Wushu teaching strategy is the overall consideration of the preparation, teaching behaviour and media selection of the teaching activities for the completion of martial arts teaching tasks. Generally speaking, Wushu teaching strategies are indicative and flexible rather than formal and stereotyped.

Wushu teaching strategy must be designed and developed into a certain strategic plan, which has strong operability. The design and formulation of Wushu teaching strategies include the preparation of martial arts teaching

The strategy, the design of Wushu teaching organization, the selection and application of martial arts teaching methods, the strategies of Wushu classroom management, the selection and application of martial arts teaching media, and the application of five aspects. Among them, the preparation strategy of Wushu teaching includes preparing lesson, saying class and thinking of three parts, which is the preparatory part of the design and formulation of Wushu teaching strategy. Preparing lessons, talking lessons, and thinking that class is not discrete, always intertwined; the final embodiment of the preparation strategy of Wushu teaching is the teaching case, which should reflect the personality of the martial arts teacher in accordance with the requirement of management. Design of martial arts teaching organization form is Wushu teachers and students to achieve the teaching goal and the social form, can be neatly according to the overall design of the whole strategy chooses the class collective organization or group teaching in the class. Martial arts teaching method selection and use of martial arts teaching activities should clearly reflect the bilateral sex, in consideration of the martial arts teaching aim, teaching material contents, the actual situation of students and teachers themselves based on the condition of choice to use, at the same time should pay attention to the wholeness of martial arts teaching method, enlightening, innovative and flexible. The management strategy of Wushu classroom is not only the basic guarantee for the successful teaching of Wushu classroom teaching, but also an effective way to improve the teaching quality. Martial arts teachers must strengthen education, discipline education and the purpose of students' education, cultivate interest in martial arts, and take full advantage of the characteristics of martial arts, continuously enhance attraction, overcome weariness of students, play its leading role, at the same time to optimize the environment of teaching, foster a good class. 
The wind; Wushu teachers should implement the management strategies in the classroom routine and classroom problems. Martial selection and application of teaching media should abide by practical, accurate, beautiful, the principle of economy and the innovation, met in learning law conforms to the education guiding ideology, martial arts and martial arts under the premise of teaching practice, comprehensive visual, hearing, seeing and hearing or synthetically teaching media.

\section{CONCLUSION}

The paper starts from urban and rural martial arts teaching development and martial arts cultural inheritance two aspects, utilizes comparative analysis method, analyzes urban and rural martial arts teaching existing gaps. Firstly, it studies urban and rural martial arts teaching development, by deepening analysis of urban and rural martial arts course setup forms, curricular class hours, curricular setup items, finds out that urban and rural martial arts teaching have great gaps, city martial arts teaching course setup forms are relative plentiful, arranged class hours are more, and items' contents selectivity is stronger, by comparing, rural martial arts teaching is far away from that in city. Secondly, utilize relative number comparison method to research on martial arts cultural inheritance. By deepening analysis of urban and rural sports teachers' attitudes towards martial arts teaching, urban and rural students' martial arts comprehension conditions and paths, it states martial arts cultural inheritance issue among urban and rural martial arts teaching process, and further gets conclusion targeted at comparison of urban and rural gaps that city martial arts development and martial arts cultural inheritance is far surpassing that in village, no matter for students or teachers, their martial arts teaching comprehension paths, behavioral attitudes are better than that among rural teachers and students, and their comprehension paths are very extensive.

The effectiveness of martial arts teaching martial arts teaching is the key to the difficulty in the theoretical study and teaching practice, the martial arts teaching strategies for the issue from introduced in sports teaching strategy, its value is to be able to really become a martial arts teaching effectiveness of the solution. Only by understanding the concept, characteristics, structure, type and formulation of Wushu teaching strategy can we apply it reasonably in the practice of Wushu teaching in order to improve the effect of Wushu teaching.

\section{ACKNOWLEDGEMENTS}

This paper is the research result of the humanities and social science research project (13G076) of Hubei provincial education department.

\section{REFERENCES}

Atapattu, T., Falkner, K., \& Falkner, N. (2017). A comprehensive text analysis of lecture slides to generate concept maps. Computers \& Education, 115, 96-113. doi:10.1016/j.compedu.2017.08.001

Ballou, D., \& Springer, M. G. (2017). Has NCLB Encouraged Educational Triage? Accountability and the Distribution of Achievement Gains. Education Finance and Policy, 12(1), 77-106. doi:10.1162/EDFP_a_00189

Chase, C. C., \& Klahr, D. (2017). Invention Versus Direct Instruction: For Some Content, It's a Tie. Journal of Science Education and Technology, 26(6), 582-596. doi:10.1007/s10956-017-9700-6

Cochrane, T., \& Davey, R. C. (2017). Mixed-Methods Evaluation of a Healthy Exercise, Eating, and Lifestyle Program for Primary Schools. Journal of School Health, 87(11), 823-831. doi:10.1111/josh.12555

Dai, G. (2012). The Attribute Conceptualizing System and Boundary of Sports Consumption. Journal of Capital College of Physical Education, 24(4), 340-345, 349. doi:10.3969/j.issn.1009-783X.2012.04.012

Ding, L., Kim, C., \& Orey, M. (2017). Studies of student engagement in gamified online discussions. Computers $\mathcal{E}$ Education, 115, 126-142. doi:10.1016/j.compedu.2017.06.016

Eitel, A., Benito, S. M., \& Scheiter, K. (2017). Do it twice! Test-taking fosters repeated but not initial study of multimedia instruction. Learning and Instruction, 5, 236-45. doi:10.1016/j.leaminstruc.2017.04.003

Falloon, G. (2017). Mobile Devices and Apps as Scaffolds to Science Learning in the Primary Classroom. Journal of Science Education and Technology, 26(6), 613-628. doi:10.1007/s10956-017-9702-4

Geller, E. H., Son, J. Y., \& Stigler, J. W. (2017). Conceptual explanations and understanding fraction comparisons. Learning and Instruction, 52, 122-129. doi:10.1016/j.learninstruc.2017.05.006

Guterman, O. (2017). What Makes a Social Encounter Meaningful: The Impact of Social Encounters of Homeschooled Children on Emotional and Behavioral Problems? Education and Urban Society, 49(8), 778-792. doi:10.1177/0013124516677009

Hsieh, W. M., \& Tsai, C. C. (2017). Taiwanese high school teachers' conceptions of mobile learning. Computers $\mathcal{E}$ Education, 115, 82-95. doi:10.1016/j.compedu.2017.07.013 
Kant, J. M., Scheiter, K., \& Oschatz, K. (2017). How to sequence video modeling examples and inquiry tasks to foster scientific reasoning. Learning and Instruction, 52, 46-58. doi:10.1016/j.learninstruc.2017.04.005

Kinkead-Clark, Z. (2017). Bridging the Gap between Home and School Perceptions of Classroom Teachers and Principals: Case Studies of Two Jamaican Inner-City Schools. Education and Urban Society, 49(8), 762-777. doi:10.1177/0013124516658951

Lai, P. K., Portolese, A., \& Jacobson, M. J. (2017). Does sequence matter? Productive failure and designing online authentic learning for process engineering. British Journal of Educational Technology, 48(6), 1217-1227. doi:10.1111/bjet.12492

Lam, R., \& Muldner, K. (2017). Manipulating cognitive engagement in preparation-to-collaborate tasks and the effects on learning. Learning and Instruction, 52, 90-101. doi:10.1016/j.learninstruc.2017.05.002

Li, P. C., Mei Y. L. (2017). The Aesthetic Thought of Competitive Sports and the Value Study of Aesthetic Education in Health Education. Eurasia Journal of Mathematics Science and Technology Education, 13(8), 5115-5121. doi:10.12973/eurasia.2017.00986a

Li, X. P., Xu, M. H., Zhao, F. N., Zhang, L., \& Zhang, G. Z. (2017). Research on the Construction of Ecological System of Internet Learning Resources for Postgraduates. Academic Degrees E Graduate Education, (4), 26-30. doi:10.16750/j.adge.2017.04.006

Luo, N., Zhang, M. L., \& Qi, D. (2017). Effects of different interactions on students' sense of community in e-learning environment. Computers \& Education, 115, 153-160. doi:10.1016/j.compedu.2017.08.006

Lv, H. T. (2011). On Cheng Dengke's National Physical Education Ideology. Journal of Hunan University of science technology, 14(2), 139-142. doi:10.3969/j.issn.1672-7835.2011.02.029

Mayer, C. (2017). Written Forms of Signed Languages: A Route to Literacy for Deaf Learners. American Annals of the Deaf, 161(5), 552-559.

McLean, K., Edwards, S., \& Morris, H. (2017). Community playgroup social media and parental learning about young children's play. Computers $\mathcal{E}$ Education, 115, 201-210. doi:10.1016/j.compedu.2017.08.004

Paredes, V. (2017). Grading System and Student Effort. Education Finance and Policy, 12(1), 107-128. doi:10.1162/EDFP_a_00195

Parks-Stamm, E. J., Zafonte, M., \& Palenque, S. M. (2017). The effects of instructor participation and class size on student participation in an online class discussion forum. British Journal of Educational Technology, 48(6), 12501259. doi:10.1111/bjet.12512

Scott, K. M., Baur, L., \& Barrett, J. (2017). Evidence-Based Principles for Using Technology-Enhanced Learning in the Continuing Professional Development of Health Professionals. Journal of Continuing Education in the Health Professions, 37(1), 61-66. doi:10.1097/CEH.0000000000000146

Sit, S. M., \& Brudzinski, M. R. (2017). Creation and Assessment of an Active e-Learning Introductory Geology Course. Journal of Science Education and Technology, 26(6), 629-645. doi:10.1007/s10956-017-9703-3

Taggart, A. (2017). The Role of Cultural Discontinuity in the Academic Outcomes of Latina/o High School Students. Education and Urban Society, 49(8), 731-761. doi:10.1177/0013124516658522

Zhang, B., \& Peng, P., (2017). Research on the Development of Education Resources for the Internet Plus Universities in the National Health Field. Eurasia Journal of Mathematics Science and Technology Education, 13(8), 5085-5093. doi:10.12973/eurasia.2017.00984a

Zheng, G. H. (2015). The Role of Endurance Contests in the Construction of Authority and Social Order in Rural China: Cases in the Qing Dynasty and the Republic of China. The International Journal of the History of Sport, 32(8), 1057-1070. doi:10.1080/09523367.2015.1022719

\section{http://www.ejmste.com}

